\title{
Molecular Epidemiology of Enteroaggregative Escherichia coli (EAEC) Isolates of Hospitalized Children from Bolivia Reveal High Heterogeneity and Multidrug-Resistance
}

\author{
Enrique Joffré ${ }^{1,2}$ and Volga Iñiguez ${ }^{2}$ \\ ${ }^{1}$ Center of Translational Microbiome Research (CTMR), Microbiology, Tumor and Cell Biology \\ (MTC), Karolinska Institutet, Stockholm, Sweden. \\ ${ }^{2}$ Instituto de Biología Molecular y Biotecnología (IBMB), Carrera de Biología, Universidad Mayor de \\ San Andrés (UMSA), La Paz, Bolivia.
}

*Corresponding author:

enrique.joffre@ki.se (EJ)

Keywords: Enteroaggregative E. coli; infant diarrhea; genetic diversity; severity; multidrug-resistance E. coli; Bolivia

\begin{abstract}
Enteroaggregative Escherichia coli (EAEC) is an emerging pathogen frequently associated with acute diarrhea in children and travelers to endemic regions. EAEC was found the most prevalent bacterial diarrheal pathogen from hospitalized Bolivian children less than five years of age with acute diarrhea from 2007 to 2010. Here, we further characterized the epidemiology of EAEC infection, virulence genes, and antimicrobial susceptibility of EAEC isolated from 414 diarrheal and 74 non-diarrheal cases. EAEC isolates were collected and subjected to a PCR-based virulence gene screening of seven virulence genes and a phenotypic resistance test to nine different antimicrobials. Our results showed that atypical EAEC (a-EAEC, AggR-negative) was significantly associated with diarrhea (OR, 1.62, $95 \% \mathrm{CI}, 1.25$ to $2.09, \mathrm{P}<0.001$ ) in contrast to typical EAEC (t-EAEC, AggR-positive). EAEC infection was most prevalent among children between $7-12$ months of age. The number of cases exhibited a biannual cycle with a major peak during the transition from warm to cold season (April June). Both typical and a-EAEC infections were graded as equally severe; however, t-EAEC harbored more virulence genes. aap, irp2, and pic were the most prevalent genes. Surprisingly, we detected $60 \%$ and $52.6 \%$ of multidrug resistance (MDR) EAEC among diarrheal and non-diarrheal cases. Resistance to ampicillin, sulfonamides, and tetracyclines was most common, being the corresponding antibiotics, the ones that are frequently used in Bolivia. Our work is the first study that provides comprehensive information on the high heterogenicity of virulence genes in t-EAEC and a- EAEC and the large prevalence of MDR EAEC in Bolivia.
\end{abstract}




\section{Author summary}

Enteroaggregative Escherichia coli is a bacterial pathogen causing acute and prolonged diarrhea in all groups of ages. In low-income countries such as Bolivia, this pathogen is the leading cause of hospitalization of children less than five years of age due to acute diarrhea. During four years of diarrheal disease surveillance, in two cities of Bolivia, we isolated 414 diarrheal and 74 non-diarrheal isolates of EAEC from hospitalized children. We classified the bacterial isolates as typical and atypical EAEC and evaluated these two groups in terms of the epidemiology, associated clinical manifestations, virulence factors, and antimicrobial resistance. We demonstrated that the atypical-EAEC subgroup was significantly associated with diarrhea, and the infection caused by this subgroup was graded severe, similar to those caused by typical EAEC. We also identified a significant number of isolates from both diarrheal and non-diarrheal cases resistant to more than three antimicrobials (multi-resistant isolates). This study has shown to the scientific community and health workers the importance of EAEC and EAEC-subtypes in diarrheal disease among children in Bolivia and highlighted the high prevalence of multidrug-resistant EAEC isolates.

\section{Introduction}

The diarrheal disease remains a significant public health problem, and it is the third leading cause of child mortality globally. In countries from Sub-Saharan Africa, South Asia, and Latin America, diarrhea is a major cause of death among children younger than two years of age (1). Enteroaggregative Escherichia coli (EAEC) is an emergent bacterial pathogen implicated in endemic diarrhea in developing and developed countries and causing acute and persistent diarrhea (>14 days) in children and adults (2). In some countries of the developing world, EAEC was one of the most prevalent agents associated with diarrhea in children less than five years of age (3-7). During EAEC infection, the clinical manifestations are often characterized by watery or mucoid diarrhea with or without blood and low-grade fever. EAEC colonizes the small and large bowels and can lead to mild inflammation in the colon (8). Long-term consequences of EAEC colonization cause growth retardation among children with or without diarrhea (9).

The gold standard for EAEC identification is the detection of the aggregative adherence (AA) pattern on HEp-2 /HeLa cells. It requires specific laboratory conditions, and it is time-consuming; therefore, molecular techniques such as PCR amplification are a great advantage, particularly in developing settings for extensive epidemiological studies (10). EAEC expresses a heterogeneous array of virulence factors encoded on the bacterial chromosome or the EAEC-specific pAA plasmid, associated with the bacteria's ability to aggregate (AA) (11-13). Each virulence gene plays a role in the disease, although the pathogenesis of EAEC infection has not been entirely resolved (14). For EAEC identification by PCR, numerous virulence genes were used as virulence markers; however, the plasmid genes aatA (pCVD432) and/or aggR were widely used among epidemiologic studies $(10,15,16)$. An increasing number of studies have complemented the chromosomal gene aaiC (12, 17-20).

The pAA plasmid harbors the transcriptional activator of the AraC/XylS class called AggR, which regulates the expression of the aggregative adherence fimbriae (AAFs: AAF/I; aggA, AAF/II; aafA, $\mathrm{AAF} / \mathrm{III}$; agg3A, AAF/IV; aff4A and AAF/V; agg5A) are involved in EAEC adherence to the intestinal epithelium (21-23). Based on the presence of the $a g g R$ gene, strains of EAEC can be classified into typical (aggR-positive) and atypical strains ( $a g g R$-negative) (24). Other plasmid genes regulated by AggR are dispersin (aap) (25) and the dispersin translocator Aat (aatA) (26). The chromosomeencoded AAI (aai) type VI secretion system was also reported to be regulated by AggR (24). The nonAggR-regulated plasmid virulence genes are the EAEC heat-stable enterotoxins 1 (EAST1; astA) (27) 
and the plasmid-encoded toxin (Pet; pet) (28). Other virulent genes are located on the bacterial chromosome, such as a 116-kDa secreted mucinase (Pic; pic) (29) and yersiniabactin biosynthesis (irp2) (30). These factors are not present among all EAEC strains and often are found in EAEC isolates from non-diarrheal cases. A later study has shown that EAEC isolates can carry additional putative virulence genes described in other pathogenic E.coli strains (31). Virulence genes of EAEC vary geographically, contributing to EAEC heterogeneity and making the identification of EAEC challenging (32).

Treatment of bacterial diarrhea use as a universal method of oral rehydration (ORS) therapy (33), intravenous fluids, breastfeeding, continuous feeding, zinc tablets, and community-based management practices by parents/guardians (34). Antibiotics treatment is usually restricted to bloody diarrhea and cholera cases with severe dehydration, but antibiotics are nevertheless frequently prescribed (35). Thus, antimicrobial-resistant $E$. coli has become a worldwide health concern, especially in developing nations where the unregulated sale of antibiotics, patients' expectations, rising income, and limited public health response have helped drive the emergence of resistance (36). The rapid increase of resistance in diarrheal pathogens pose a serious threat (37).

In our previous study (7), EAEC was the most prevalent diarrheagenic E. coli causing $11 \%$ of all hospitalizations for acute diarrhea among children less than five years old. This report highlighted the importance of EAEC as an emerging pathogen in the region and the urge to be followed up. The collection of EAEC isolates from children with or without diarrheal disease from two main cities of Bolivia was further characterized, and to our best awareness, no studies focusing on EAEC characterization have been done yet in Bolivia. Hence, this study aims to investigate different aspects of the EAEC infection such as seasonality and disease severity and the prevalence of selected virulence genes and antimicrobial resistance (AMR) of the circulating EAEC isolates.

\section{Methods}

\section{Fecal samples}

From January 2007 to December 2010, a total of 3943 stool samples of hospitalized children less than five years with acute diarrhea were collected as part of the National Diarrhea Surveillance (NDS), which included five hospitals in two cities in Bolivia (La Paz: Hospital Materno Infantil, Boliviano Holandés, Hospital del Niño, and Hospital Los Andes, and Cochabamba: Albina Patiño). In parallel, stool samples of 1026 children less than five years, with no diarrhea record, were collected (7). The NDS aimed at the evaluation of main diarrheagenic E. coli (DEC), such as enteroaggregative E. coli (EAEC), enterotoxigenic E. coli (ETEC), enteropathogenic E. coli (EPEC), enterohaemorrhagic E. coli (EHEC), and enteroinvasive E. coli (EIEC). Stool samples where EAEC was isolated as sole DEC pathogen were included in this study for further PCR screening of virulence genes and antibiotic susceptibility tests.

\section{Clinical manifestations, the severity of the disease, and weather information}

Data of patients enrolled in the study for characterization of the population study, e.g., age, sex, and date of hospitalization, as well as the features of acute diarrhea for the evaluation of the severity of the disease, were collected from the patient's clinical records obtained from the different participating hospitals. A Vesikari score was adapted to evaluate the severity of diarrhea, as was described by 
Gonzales, Joffre (7). The score included duration of diarrhea (1 to 3 points), the maximum frequency of stools per day ( 0 to 3 ), the maximum frequency of vomits per day (0 to 3 ), dehydration (0 to 4$)$, treatment by oral or intravenous rehydration (1 to 3), presence of metabolic acidosis ( 0 to 2 ), and electrolytic disequilibrium ( 0 to 2 ). The total of points per patient was classified based on the score as follows. Mild severity from 0 to 8 points; moderate from 9 to 14 and severe from 15 to 20, 20 the top score.

For analysis of the seasonal distribution of EAEC infection, data concerning temperature and precipitation were extracted from the National Service of Hydrology and Meteorology of Bolivia (SENAHM) (http://senamhi.gob.bo/index.php/inicio).

\section{Bacterial isolation and EAEC identification}

Cary-Blair tubes containing feces swaps were transported from the hospitals to the laboratories at the Instituto de Biología Molecular y Biotecnología (IBMB) in La Paz to be cultured on E. coli Medium (EC) and streaked onto MacConkey agar for isolation of lactose-positive fermenting bacterial colonies. As was described elsewhere(7), five colonies per sample were collected, the DNA extracted by boiling $\left(15 \mathrm{~min}\right.$ at $\left.99^{\circ} \mathrm{C}\right)$, centrifuged, and the supernatant polled for gene-targeted PCR assay using the gene $a a t A$ as a virulence marker for EAEC identification. Samples aatA-positive were stored at $-70^{\circ} \mathrm{C}$ in Trypticase soy broth (TSB) containing $15 \%$ glycerol for further PCR characterization.

\section{Detection of virulence factors by PCR}

For identifying EAEC virulence genes, the bacterial DNA from each isolate was extracted as was described above, and the supernatant used as a template for targeting seven virulence genes using two panels of multiplex-PCR assays and one single PCR (Table 1). PCR products were electrophoresed onto gels with 2.5\% Agarose, and the DNA bands were visualized and photographed under UV light after staining with ethidium bromide. EAEC strain 042 and 17-2 have been used as a positive control (38), and nonpathogenic E. coli K12 (ATCC 47076) has been used as a negative control for the PCR assay.

Table 1. Primers used in this study

\section{Antibiotic resistance test}

The determination of the sensibility to antibiotics was done using the disk diffusion method according to the Clinical and Laboratory Standards Institute (CLSI) guidelines(Wayne 2011). The following antibiotic disks were used: ampicillin (25g), ampicillin-sulbactam $(20 \mathrm{~g})$, cefotaxime (30g), cefoxitin $(30 \mathrm{~g})$, ciprofloxacin $(5 \mathrm{~g})$, chloramphenicol $(30 \mathrm{~g})$, nalidixic acid $(30 \mathrm{~g})$, tetracycline $(30 \mathrm{~g})$ and sulfamethoxazole-trimethoprim (19:1) (Oxoid®). The Escherichia coli ATCC® 25922 and Staphylococcus aureus ATCC® 25923 were used as reference strains. Strains that exhibit resistance to one or more agents in the last three different antimicrobial categories are considered multidrug-resistant (MDR) (39).

\section{Ethical permits}

The present study was conducted as part of the Diarrheal Disease Project and the National Rotavirus Surveillance program in Bolivia. The Bolivian National Bioethics Committee granted both programs' ethical permit to collect stool samples from children less than five years of age hospitalized with or without acute diarrhea for identification of bacterial and viral diarrheagenic pathogens (7). Upon arrival at the hospital, the parents or guardians of the children were informed about the purpose of the study, asked to participate, and provide their oral consent to collect and analyze the fecal samples from the 
participants, including the clinical information of the hospitalization symptoms. The sample collection was non-invasive and directly taken after deposition or from the diapers. Participant data and/or specimens were anonymous and stored without the collection of any identification that may link to a specific individual. Oral informed consent was requested instead of the written form since parents or guardians of the participants may be illiterate due to the lack of formal education. The same procedure for all the participants was carried out. All information was given either in Spanish or their native language, i.e., Aymara or Quechua.

\section{Statistical analysis and data visualization}

The program GraphPad Prism version 8.4.2 was used to evaluate the statistical significance of the differences between the groups by the $\chi 2$-test or Fisher's exact test (whenever necessary). All $p$ values reported are two-sided. $\mathrm{p}<0.05$ was considered to be statistically significant. The virulence gene profile and the antimicrobial resistance test data were used to generate cluster analysis and evaluate relatedness between EAEC isolates. For data conversion, score one was given for the presence of a gene or phenotypic resistance to a specific antibiotic, and the score 0 was given when the isolate lacks the virulence gene, or the isolate was considered susceptible. The euclidian distance was used for clustering, and the heatmaps were generated using the $\mathrm{R}$ package pheatmap v1.012. Bar plots for time series plots of EAEC seasonal distribution were generated using the R package ggplot 2 .

\section{Results}

\section{Atypical EAEC is associated with diarrhea}

From the 3943 stool samples collected from children with an acute diarrheal disease during the 4-year study period (2007-2010) and including two cities of Bolivia (La Paz and Cochabamba), EAEC was detected in 440 stool samples (11.2\%) as a single associated diarrheagenic E. coli using aatA-specific PCR assay. In parallel, 74 EAEC isolates (7.2\%) were detected from 1026 non-diarrheal stools from hospitalized children admitted for a reason other than acute diarrhea. Among EAEC isolates, we targeted the $a g g R$ gene as a PCR marker to identify the EAEC subtypes: typical (aggR positive) and atypical ( $\operatorname{ggg} R$ negative). Our data from Table 2 revealed that from the total cases of diarrhea, 254 $(6.4 \%)$ were caused by atypical EAEC (a-EAEC), while 186 (4.7\%) were typical EAEC (t-EAEC). Typical and atypical EAEC isolates were also identified in the same proportion within the non-diarrheal cases. Similar to EAEC, a-EAEC isolates were found to be associated with diarrhea (OR, 1.62, 95\% CI, 1.25 to 2.09, $\mathrm{P}<0.001$ ) in contrast to t-EAEC (Table 2).

Table 2. Prevalence of EAEC and EAEC subtypes among diarrheal and non-diarrheal cases from Bolivian children less than five years of age included in the study.

\section{High prevalent of EAEC infections during the cold-dry season and among younger children}

The age distribution of the children enrolled in the study indicated that $91.1 \%(n=401)$ of the diarrheal cases were among children less than two years of age. In non-diarrheal cases, the percentage was $63.5 \%$ $(\mathrm{n}=47)$. As it is shown in Figure 1a and S Table 1, EAEC was most prevalent among children between seven to twelve months of age (41.8\%), followed by the children older than 12 months (40.9\%) and younger than seven months $(17.3 \%)$. Age distribution between diarrheal cases of t-EAEC or a-EAEC was similar, except with children between 7-12 months of age that were statistically twice more likely to be infected by a-EAEC (OR $2.08,95 \% \mathrm{CI}, 1.05$ to $4.26, \mathrm{P}=0.0369$ ).

The temporal and seasonal distribution, e.g., warm-humid or cold-dry, of the diarrheal cases of EAEC in conjunction with the age groups, were evaluated per year and globally. As shown in Figure 
1b, EAEC-related cases had a biannual cycle with a major peak during the cold-dry season (from May to September) and a minor peak in October where the transition from cold-dry to warm-humid season occurs. The biannual cycle is evident in Figure 1c, showing the cumulative number of EAEC cases from the whole study period. EAEC's major peak started earlier in 2007 and 2008, but in 2009 and 2010 shifted towards the coldest month of the year (June and July). The minor peak continually stroked after the end of the cold-dry season (October). On average, EAEC's peaks had a periodicity of 3.5 months (3-5 months). We did not find any specific statistical association between the number of cases of EAEC (typical and atypical) and season (cold-dry or warm-humid season) (S Table 2).

\section{Typical and atypical EAEC isolates caused equally severe diarrhea in children.}

Later, we classified the EAEC into these two groups and compared the clinical manifestations and the typical and atypical EAEC associated diarrhea severity. The typical EAEC (t-EAEC) isolates are usually considered more virulent than atypical EAEC (a-EAEC) $(6,24)$. Only 159 cases of EAEC diarrhea counted with completed clinical data, of which 81 were typical and 78 atypical EAEC. As is summarized in Table 3, pediatric patients infected either with t-EAEC or a-EAEC had similar clinical characteristics and disease severity, and no statistical differences were found. However, we noticed that t-EAEC tended to cause more moderate cases (72\%) than a-EAEC $(67.9 \%)$.

Table 3. Clinal symptoms and severity scores of pediatric subjects with diarrhea caused by t-EAEC or a-EAEC among Bolivian children.

\section{Typical EAEC isolates harbor more virulence genes than atypical EAEC}

We screened for seven virulence genes among the t-EAEC and a-EAEC isolates from diarrheal and non-diarrheal cases, including plasmid-borne (aap, astA, aggA, aafA, and pet) and chromone-encoded virulence genes (irp2, pic). The results summarized in Table 4 showed that aap, irp2, and pic were the most prevalent among all EAEC isolates and present in more than $50 \%$ of the isolates. The genes irp2 $(\mathrm{P}=0.001)$ and aafA $(\mathrm{P}=0.039)$ were significantly more prevalent among diarrheal EAEC isolates than non-diarrheal EAEC isolates. The rest of the virulence genes were equally identified among diarrheal and non-diarrheal isolates. The combination aap, irp2, and pic was the most prevalent virulence genotype in diarrheal isolates $(7.3 \%)$, while pic-only was the most prevalent in the nondiarrheal isolates (8.1\%) (S Table 3). The genes astA, aggA, aafA, and pet were found to a lesser extent. Within EAEC isolates from diarrheal cases, the genes aap $(\mathrm{P}=0.002)$ and aafA $(\mathrm{P}=0.02)$ were significantly more common in t-EAEC and not a-EAEC. The aap gene was also more common in nondiarrheal t-EAEC than a-EAEC (Table 4).

Table 4. Prevalence of virulence genes of EAEC isolated from diarrheal and non-diarrheal cases among Bolivian children.

Based on the number of virulence genes detected per strain, an average of 3.1 virulence genes/isolate in isolates from diarrheal cases was estimated, while non-diarrheal isolates harbored $2.6(\mathrm{P}<0.05)$. tEAEC and a-EAEC isolates harbored in average 3.4 genes/isolate and 2.8 genes/isolate $(\mathrm{P}<0.01)$, respectively. The lowest number of genes per isolate was found among non-diarrheal a-EAEC isolates with 2.3 genes/isolate vs. the three genes/isolate from the non-diarrheal t-EAEC isolates $(\mathrm{P}<0.001)$ (Figure $2 \mathrm{a}$ and $\mathrm{b}$ ). Fourteen $(3.2 \%)$ diarrheal and one non-diarrheal (1.4\%) isolates were negative to all the virulence genes included in this study (S Table 3).

In Figure 2c, we constructed a heatmap to screen the distribution of virulence genes found on t-EAEC and a-ETEC isolates along the four-year study period and whether specific profiles were associated with diarrheal cases. The clustering patterns of virulence genes did not reveal a particular clustering of diarrheal or non-diarrheal isolates, indicating that similar profiles of virulence genes circulated 
throughout the study period and between diarrheal and non-diarrheal cases. Two clusters were identified, of which cluster II enclosed most of the t-EAEC isolates characterized by having a more extensive number of virulence genes, as we showed previously. Cluster I, on the other hand, included the majority of a-EAEC. The genes pic, aap, and irp2 were more likely to be found together than the rest of the virulence genes, and both t-EAEC and a-EAEC isolates shared them. The astA, aggA, aafA, and pet were more restricted to t-EAEC isolates, which harbors the master regulator agg $R$ and regulates fimbrial genes (aggA and aafA). These data suggest that the composition between typical and atypical isolates is not entirely different, and they share many virulence genes. Still, there is a specific combination of virulence genes that branch them apart.

\section{High prevalence of MDR in EAEC isolated from diarrheal and non-diarrheal cases}

Susceptibility testing of the diarrheal and non-diarrheal EAEC isolates to 9 different antibiotics revealed resistance to all of the antimicrobials tested with multidrug-resistance (MDR) in more than half of the isolates. For example, $60 \%$ of diarrheal and $52.6 \%$ of non-diarrheal isolates were multidrugresistant, meaning they were resistant to at least three classes of antimicrobials, and $2.7 \%$ and $7 \%$ were resistant to the six antibiotics classes tested; however, no statistical differences were found between these two groups (Table 5 and Figure 3a). Resistance to cephalosporins such as cefoxitin and cefotaxime were significantly lower among diarrheal isolates than non-diarrheal isolates. In contrast, significantly more diarrheal isolates were resistant to the older antimicrobial sulfamethoxazoletrimethoprim than non-diarrheal isolates $(\mathrm{P}=0.0024)$. Between $\mathrm{t}-\mathrm{EAEC}$ than a-EAE, the first had twice more resistant isolates to cefotaxime than the atypical subtype $(\mathrm{P}<0.05)$. Overall, the $\beta$-lactam antibiotic ampicillin reported the highest number of resistant isolates, followed by sulfonamides and tetracyclines. Resistance to fluoroquinolones, especially ciprofloxacin, which is considered widely used to treat diarrhea in Bolivia, was the lowest (Table 5). The heatmap of the temporal distribution of AMR profiles in Figure 3 showed co-occurrence of resistant phenotypes of penicillins (ampicillin or ampicillin-sulbactam) and tetracycline (tet) or sulphonamides (stx), which could be due to the acquisition of AMR genes co-transferred via mobile elements. MDR isolates did not show any particular clustering pattern regarding the year of isolation, diarrheal or non-diarrheal cases, or EAEC subtype type.

Table 5. Prevalence of AMR phenotypes of EAEC isolated from diarrheal and non-diarrheal cases among Bolivian children.

\section{Discussion}

This study represents the first comprehensive report of the characterization of diarrhea caused by EAEC (typical or atypical). The phenotypic and genotypic heterogeneity of the bacterial isolates recovered from acute diarrheal and non-diarrheal cases from Bolivian children during four-year surveillance of diarrheagenic bacteria in two Bolivian cities. In our previous study (7), EAEC was found as the most prevalent diarrheagenic E. coli associated with acute diarrhea in Bolivian children, and the study of this pathovar is highly relevant to the region. Similar studies in other countries in Latin America, i.e., Peru (40, 41), Brazil (42, 43), and Paraguay (44), have reported EAEC as the most isolated bacterial pathogen from children with acute diarrhea. Other studies associate EAEC with persistent diarrhea, sporadic outbreaks in industrialized nations, and adult travelers to endemic regions suggest that this emergent pathogen is highly heterogeneous (44).

Several studies indicate a significant heterogeneity of virulence markers among EAEC isolates, and its detection can be challenging. Here we used the aatA gene, which corresponds to the former EAEC probe CVD432, as a marker to identify EAEC. Further identification of the $a g g R$ gene's presence 
allowed us to classify the EAEC isolates into typical and atypical EAEC, similar to other studies (6, 45-47). The prevalence of the a-EAEC was surprisingly higher and significantly associated with diarrhea compared with t-EAEC and non-diarrheal EAEC isolates. The majority of the epidemiological studies have reported t-EAEC isolates as the predominant subtype of EAEC isolated associated with the disease $(6,32,45,48)$, while other studies have not been able to associate t-EAEC (AggR-positive) with diarrhea $(19,49,50)$. Therefore the association of $a g g R$-positive strains and diarrhea is not consistent.

EAEC infection was more prevalent among children with diarrhea less than two years of age, with two epidemiological peaks during the seasonal transition. The first EAEC peak of April, May, and June, overlapped with the maximum number of hospitalizations related to diarrhea, being a large proportion of them due to rotavirus, as we previously reported (7). Also, we observed that other bacterial pathogens such as ETEC had a peak in May and a dramatic reduction of cases towards August. Along the Bolivian Andes, this period is characterized by an important reduction of temperature and rainfall, where the coldest nights are often reported. Our observation of a large peak in the transition to winter contrasts the notion that infections caused by bacterial pathogens are mostly associated with warmer and humid months (or summer), where conditions such as high temperature, rain, and humidity favor bacterial proliferation and propagation (51). For example, the GEMS study focused on pathogens with a strong association with diarrhea, such as ETEC secreting ST associated with warm and rainy weather in Asia (Pakistan, India, and Bangladesh) and an African country (Mozambique) (52). A four-year follow-up of EAEC prevalence allowed us to observe biannual periodicity, with approximately 4-5 months gap between the peaks that could suggest that seasonal transition might play an indirect role in EAEC prevalence, that could facilitate the transmission of the pathogen into the population. Additional socioeconomic factors such as crowded settings or households with poor hygiene, sanitation, and contaminated water could exacerbate the propagation of EAEC during the cold-dry season. Studies with more recent EAEC prevalence data need to be considered to evaluate whether the biannual periodicity of EAEC remains univariable even after the severe consequences of climate change and water management that La Paz and Cochabamba cities experienced in the last decade (53).

The severity of the diarrheal illness in children by EAEC was evaluated and compared between typical and atypical subtypes with no differences found. Several studies have found an association of t-EAEC strains with diarrhea $(6,54-58)$ and highlighted that the presence of the master regulator aggR is critical for EAEC pathogenesis (adherence, biofilm formation, colonization, and persistence in the intestinal gut) (32) while others not $(12,18,19)$. Our data reinforce the notion that EAEC is a very heterogeneous pathogen causing a wide range of symptoms due to being highly diverse in virulence determinants. Other DECs pathogens (ETEC and EPEC) also detected in our surveillance and reported by Gonzales, Joffre (7) reached similar severity scores. EAEC has been associated with diarrhea as a sole pathogen or in co-infections (7). Although our analysis of the severity of the disease excluded cases of coinfection, e.g., EAEC-rotavirus, or EAEC-ETEC, other pathogens not tested in the surveillance (i.e., norovirus, Shigella, Campylobacter, Salmonella, Yersinia species or parasites) might have contributed to some extent to the symptoms and masked potential true differences in the severity score between EAEC subtypes. EAEC infection has also been associated with persistent diarrhea and gut inflammation $(9,10)$. Boll and McCormick (59) reported that the inflammatory response might play an important role during EAEC infection. EAEC triggers inflammation through the intimate contact with the host epithelium mediated by the AFFs $(9,10)$. The specific association of t-EAEC isolates expressing the aafA gene (AAF/II) with diarrhea identified in this study might suggest higher inflammation levels during t-EAEC infections in contrast to t-EAEC or a-EAEC isolates that are lacking both AAF variants. Additional identification of the remaining AAF variants (AAF III-V) will improve the understanding of the role of AAFs in EAEC diarrhea and inflammation. The host 
nutritional status, such as malnourishment, has been shown to worsen EAEC infection in a murine model (60) and children (9). A substantial proportion of the children from the Bolivian population are malnourished, with stunting on 30\%, and > 40\% have anemia (61). These could aggravate diarrheal onset associated with a-EAEC isolates lacking AggR. Host factors found in the children's gut or diet might downregulate $a g g R$-regulon expression and display less virulence (24). Future studies on EAEC severity should include other pathogens of diarrheal diseases and clinical features of gut inflammation to characterize more accurately the disease caused by EAEC subtypes. Perhaps, the definition of typical and atypical based only on the presence of the $a g g R$ gene might introduce bias in the classification.

We further identified seven virulence genes of EAEC to understand better the heterogenicity of the EAEC strains circulating and evaluate potential candidates as gene markers of this pathogen. We reported remarkable heterogeneity of virulence genes, of which two out of seven genes, i.e., irp2 and aafA, were significantly associated with diarrhea. The high prevalence of irp2 was comparable with previous reports $(15,62,63)$ and highlight that siderophore production and iron scavenging is a mechanism widely used by EAEC strains. The irp 2 gene is located on a pathogenicity island, disseminated among E. coli species through horizontal gene transfer (64).

Adhesin AAF/II encoded by the aafA gene was the least prevalent adhesin and only found in $16 \%$, and $8 \%$ of EAEC isolates from diarrheal and non-diarrheal cases, respectively; however, AAF/II prevalence was higher than EAEC isolates from children in Mali (19). AAF/II association with diarrhea was reported in another two studies $(65,66)$. Lima, Boisen (18) showed that combinations of other virulence factors were not included in this study, such as aaiC, agg3/4C, agg4A, and aar (previously known as orf61), were associated with diarrhea compared to control samples. Both genes irp2 and aafA were more prevalent among our t-EAEC than a-EAEC isolates, but they scored similar severity scores suggesting that these genes alone or in a combination of the other five investigated virulence genes might (or do) not contribute to more severe diarrhea.

The aap genes that encode for dispersin was the most prevalent virulence gene among all EAEC isolates; similarly to us, other studies found aap in high proportions $(19,31,67)$. Despite the fact that dispersin was also found among other diarrheagenic E.coli pathotypes and nonpathogenic E.coli (68), several studies focused on EAEC isolates have shown that aap gene was highly prevalent virulent marker and associated with diarrheal cases $(56-58,69)$. Since the aap gene showed to be a nonexclusive EAEC virulence gene, its addition to the initial detection for EAEC will not improve the identification of EAEC isolates. Dispersin is a protein that promotes EAEC dispersion to colonize new regions of the intestine (70). Dispersin secretion depended on a translocation system called the EAEC ABC transporter (aat)(71), which previously was not described but used as a marker for EAEC identification. That could explain the high frequency of aap gene among aatA-positive EAEC isolates in our study.

Here t-EAEC harbored significantly more virulence genes than a-EAEC. Although t-EAEC harbored more virulence genes that could lead to higher virulence, t-EAEC was equally severe as a-EAEC. Several studies have also reported more genes among t-EAEC than a-EAEC isolates, but this can be because more attention has been made to characterize t-EAEC for often being associated with diarrhea (10).

The lack of $\operatorname{aggR}$ gene in half of our EAEC isolates coincide with Lima's findings, and the authors suggested that this gene is not a useful virulence marker for diagnosis in opposite to what was suggested by other studies and that this gene alone is not a sensitive target and much less specific than the aatA gene $(2,18)$. In recent years case-control and epidemiological studies have used several EAEC 
virulence genes, and aatA, aap, aagR, astA, and aafA were among the most frequently used for EAEC diagnosis (12, 20, 69). Also, Jenkins, Chart (49) suggested that aaiA, a chromosomal -encoded gene, would improve EAEC diagnosis.

AggR is a master regulator that controls many plasmid-encoded (AAFs, AggR itself, Aap and Aat) and chromosomal-encoded (pheU pathogenicity island) virulence determinants (24). The identification of AggR-regulated genes among t-EAEC strains is expected. Certain factors are co-inherited because they are coordinately regulated by AggR and/or act in concert on a common pathogenic strategy (72). A study found reduced mortality of infected $G$. mellonella larvae with $a g g R$ mutant strain and high virulence of atypical EAEC strains suggest that EAEC virulence appears to be related to the AggR regulon (73), but not exclusively as was observed here.

Among the toxins, pet was the most prevalent, followed by the astA and, to a lesser extent, pic among case and non-diarrheal isolates. Pet and Pic belong to class I and II of SPATEs extracellular proteases secreted via Type V secretion system, respectively. EAST1 encoded by astA have some similarities to STa ETEC enterotoxin, both can increase the secretion of chloride, and particularly EAST1 have been associated with secretory diarrhea $(74,75)$. These toxins were not found in all EAEC isolated from diarrheal cases, and they were also present in non-diarrheal EAEC isolates, suggesting that potentially other toxins, e.g., SHET1 encoded by set gene, or sepA (secreted autotransporter toxin) found associated with diarrheal disease (19), or the combination of multiple factors/toxins are responsible for diarrhea.

The high percentage of MDR found among clinical isolates of EAEC is of great concern and reflects an extensive misuse or overuse of antimicrobials in younger Bolivian children in opposition to WHO recommendations. The use of antibiotics early in life may influence the immune system's structure and functions and cause profound alteration in the microbiota, leading to impaired growth and increased susceptibility to infectious diseases (76). Our findings correlate with studies in Bolivia and other developing countries where widespread use of antibiotics can be purchased over the counter and without any prescription(77). Studies in La Paz showed that diarrheagenic E. coli are 60-90\% resistant to the most common antibiotics, such as ampicillin, tetracycline trimethoprim-sulfamethoxazole $(7,78$, 79). Among healthy Bolivian children, 63\% carried MDR-E. coli in their stool samples (80). Similar results were found in EAEC from children in Kenya with persistent diarrhea (81) as well as in the aEPEC isolates from the GEMS study (carried out at seven sites in South Asia and sub-Saharan Africa) (82). In particular, we observed that trimethoprim-sulfamethoxazole had been broadly used to treat diarrhea since a significant number of EAEC isolates were resistant to this antibiotic in comparison with non-diarrheal isolates. To our knowledge, there have been no reports on the antibiotic susceptibility on atypical EAEC. According to our results, ampicillin and sulfamethoxazoletrimethoprim should not be considered to be used to treat bacterial diarrhea, whereas ciprofloxacin, due to low levels of resistance among EAEC strains, can be only recommended in severe cases of EAEC infection with or without malnourishment, to decrease mortality for acute diarrhea. More recent AMR monitoring among EAEC isolates must be done before considering the antibiotic of choice for treating severely affected patients since AMR in bacterial isolates is already high and continues on the rise (77).

Finally, a possible methodological limitation of this study is that children from the non-diarrheal group were older than those with diarrhea. As EAEC is endemic in Bolivia and causes infection mainly among children younger than two years of age, children with non-diarrheal cases probably were previously exposed or infected by EAEC, resulting in the acquisition of immunity (83) or long-term 
carriers. Additional studies on the virulence of these strains isolated from non-diarrheal patients need to be done to determine whether they are truly pathogenic or not.

In conclusion, our study is the first study in Bolivia, focusing on an integral characterization of the diarrheal diseases caused by EAEC and bacterial isolates and has uncovered knowledge and understanding of the epidemiology of EAEC and its heterogeneity in the region. We showed that EAEC is a circulating endemic pathogen responsible for a large proportion of hospitalization cases for acute diarrhea in children, particularly during the transition of seasons. A large proportion of bacterial strains displayed multidrug resistance to the most frequently used antibiotics. Here we found that, contrary to what is suggested in the literature, the EAEC subtype a-EAEC lacking the transcriptional factor AggR, was responsible for most cases of diarrhea considering that $\mathrm{AggR}$ is a global virulence regulator and its presence correlated with the presence of the pAA and indicates a vast virulence arsenal. Diarrhea caused by this subtype was as severe as t-EAEC, even though the last harbored more virulence genes reported to play an important role in the diarrheal disease. To clarify the pathogenicity of a-EAEC and t-EAEC, further epidemiological and genomics studies are needed.

\section{Conflict of Interest}

The authors declare that the research was conducted in the absence of any commercial or financial relationships that could be construed as a potential conflict of interest.

\section{Author Contributions}

VI acquired the funding and administered the project. VI and EJ conceived and designed the experiments. EJ collected the data and performed the experiments, data analysis, and statistical analysis under VI supervision. EJ prepared the original draft and wrote the manuscript. VI and EJ reviewed and edited the manuscript.

\section{Funding}

The project was performed as part of the National Rotavirus Surveillance Program and UMSA-IBMB "Diarrheal Disease Project" supported by the Swedish Agency for Research Economic Cooperation (SIDA).

\section{Acknowledgments}

We thank Åsa Sjöling for comments on the manuscript. 


\section{TABLES AND FIGURES}

Table 1. Primers used in this study.

\begin{tabular}{|c|c|c|c|c|}
\hline \multirow[t]{5}{*}{ Multiplex } & Target gene & Primer sequence ( $5^{\prime}$ to $\left.3^{\prime}\right)$ & Amplicon size (bp) & Ref. \\
\hline & aatA ( $p C V D 432)$ & F: CTGGCGAAAGACTGTATCAT & 630 & $(67)$ \\
\hline & & R:CAATGTATAGAAATCCGCTGTT & & \\
\hline & $\operatorname{agg} R$ & F: CGT TCG TGA ATG CAA AG & 308 & (84) \\
\hline & & R: GAG GCA TCA CCA ATA TG & & \\
\hline \multirow[t]{6}{*}{ I-EAEC } & astA & F:CCATCAACACAGTATATCCGA & 111 & $(67)$ \\
\hline & & R:GGTCGCGAGTGACGGCTTTGT & & \\
\hline & pic & F:TTCAGCGGAAAGACGAA & 517 & $(15)$ \\
\hline & & R:TCTGCGCATTCATACCA & & \\
\hline & $\operatorname{irp} 2$ & F:AAGGTTCGCTGTTACCGGAC & 267 & (30) \\
\hline & & R:TCGTCGGGCAGCGTTTCTTCT & & \\
\hline \multirow[t]{8}{*}{ II-EAEC } & $\operatorname{agg} A$ & F:GCTAACGCTGCGTTAGAAAGACC & 421 & (15) \\
\hline & & R:GGAGTATCATTCTATATTCGCC & & \\
\hline & aafA & F:GACAACCGCAACGCTGCGCTG & 233 & (15) \\
\hline & & R:GATAGCCGGTGTAATTGAGCC & & \\
\hline & pet & F:TCATTTCCAGCACTTCCTGT & 442 & (85) \\
\hline & & R:CTCCGACAGTATTTGCTCGT & & \\
\hline & aap & F:CTTTTCTGGCATCTTGGGT & 232 & \\
\hline & & R:GTAACAACCCCTTTGGAAGT & & (67) \\
\hline
\end{tabular}


Table 2. Prevalence of EAEC and EAEC subtypes among diarrheal and non-diarrheal cases from Bolivian children less than five years of age included in the study.

\begin{tabular}{|c|c|c|c|c|c|c|c|}
\hline \multirow[t]{2}{*}{ EAEC subtype } & Diarrl & eal cases & Non-dia & rrheal cases & \multirow[t]{2}{*}{ Total } & \multirow[t]{2}{*}{ OD ratio $(95 \% \mathrm{CI})$} & \multirow[t]{2}{*}{$P$-value } \\
\hline & & $(\%)$ & $\mathrm{n}$ & $(\%)$ & & & \\
\hline EAEC & 440 & $(11.2)$ & 74 & $(7.2)$ & 514 & $1.62(1.25-2.09)$ & 0.0001 \\
\hline a-EAEC & 254 & (6.4) & 37 & (3.6) & 291 & $1.84(1.31-2.61)$ & 0.0004 \\
\hline $\mathrm{t}$-EAEC & 186 & (4.7) & 37 & (3.6) & 223 & $1.32(0.92-1.90)$ & 0.1497 \\
\hline
\end{tabular}

t-EAEC: typical EAEC, a-EAEC: atypical EAEC 
Table 3. Clinal symptoms and severity scores of pediatric subjects with diarrhea caused by t-EAEC or a-EAEC among Bolivian children.

\begin{tabular}{|c|c|c|c|c|c|c|}
\hline \multirow{2}{*}{ Variable } & \multicolumn{2}{|c|}{ Typical EAEC } & \multicolumn{2}{|c|}{ Atypical EAEC } & \multicolumn{2}{|c|}{ Total EAEC } \\
\hline & \multicolumn{2}{|c|}{$(\mathrm{n}=81)$} & \multicolumn{2}{|c|}{$(\mathrm{n}=78)$} & \multicolumn{2}{|c|}{$(n=159)$} \\
\hline Mean maximum frequency of stools per day & \multicolumn{2}{|c|}{$6.95 \pm 3.3$} & \multicolumn{2}{|c|}{$7.36 \pm 3.7$} & \multicolumn{2}{|c|}{$7.14 \pm 3.4$} \\
\hline Mean maximum frequency of vomits per day & \multicolumn{2}{|c|}{$5.17 \pm 3.1$} & \multicolumn{2}{|c|}{$4.92 \pm 3.6$} & \multicolumn{2}{|c|}{$4.79 \pm 3.5$} \\
\hline Mean no. of days with diarrhea & \multicolumn{2}{|c|}{$3.48 \pm 2.4$} & \multicolumn{2}{|c|}{$3.92 \pm 3.1$} & \multicolumn{2}{|c|}{$3.95 \pm 4.1$} \\
\hline \multicolumn{7}{|l|}{ Dehydration } \\
\hline None & 8 & $(9.9)$ & 6 & $(7.7)$ & 14 & $(8.8)$ \\
\hline Mild & 50 & $(61.7)$ & 54 & $(69.2)$ & 104 & $(65.4)$ \\
\hline Severe & 23 & $(28.4)$ & 18 & $(23.1)$ & 41 & $(25.8)$ \\
\hline \multicolumn{7}{|l|}{ Treatment } \\
\hline Oral & 17 & $(21.0)$ & 10 & $(12.8)$ & 27 & $(17.0)$ \\
\hline Intravenous & 64 & $(79.0)$ & 66 & $(84.6)$ & 130 & $(81.8)$ \\
\hline \multicolumn{7}{|l|}{ Complications } \\
\hline Electrolytic disequilibrium & 13 & $(16.0)$ & 22 & $(28.2)$ & 35 & $(22.0)$ \\
\hline Metabolic acidosis & 21 & $(25.9)$ & 24 & $(30.8)$ & 45 & $(28.3)$ \\
\hline \multicolumn{7}{|l|}{ Vesikari Score } \\
\hline Mild (0-8) & 17 & $(21.0)$ & 19 & $(24.4)$ & 36 & $(22.6)$ \\
\hline Moderate (9-14) & 59 & $(72.8)$ & 53 & $(67.9)$ & 112 & $(70.4)$ \\
\hline Severe (15-20) & 5 & $(6.2)$ & 6 & $(7.7)$ & 11 & $(6.9)$ \\
\hline Mean Vesikari score & & \pm 3.0 & & $76 \pm 2.7$ & 10.8 & $5 \pm 2.9$ \\
\hline
\end{tabular}

Numbers are mean $+/-\mathrm{SD}$ or $\mathrm{n}(\%)$ 
Table 4. Prevalence of virulence genes of EAEC isolated from diarrheal and non-diarrheal cases among Bolivian children.

\begin{tabular}{|c|c|c|c|c|c|c|c|c|c|c|c|c|c|c|c|}
\hline \multirow{3}{*}{$\begin{array}{l}\text { Virulence } \\
\text { genes }\end{array}$} & \multicolumn{4}{|c|}{ Diarrheal isolates (D) } & \multirow{2}{*}{\multicolumn{2}{|c|}{$\begin{array}{c}\text { Total } \\
(n=440)\end{array}$}} & \multirow{3}{*}{$\begin{array}{c}P \text { - } \\
\text { value } \\
\text { (D) }\end{array}$} & \multicolumn{4}{|c|}{$\begin{array}{l}\text { Non-diarrheal isolates } \\
\text { (ND) }\end{array}$} & \multirow{2}{*}{\multicolumn{2}{|c|}{$\begin{array}{c}\text { Total } \\
(n=74)\end{array}$}} & \multirow{3}{*}{$\begin{array}{c}P \text { - } \\
\text { value } \\
\text { (ND) }\end{array}$} & \multirow{3}{*}{$\begin{array}{c}P \text { - } \\
\text { value } \\
\text { (D vs } \\
\text { ND) }\end{array}$} \\
\hline & \multicolumn{2}{|c|}{$\begin{array}{l}\text { t-EAEC } \\
(n=186)\end{array}$} & \multicolumn{2}{|c|}{$\begin{array}{l}\text { a-EAEC } \\
(n=254)\end{array}$} & & & & \multicolumn{2}{|c|}{$\begin{array}{c}\text { t-EAEC } \\
(\mathbf{n}=37)\end{array}$} & \multicolumn{2}{|c|}{$\begin{array}{c}\text { a-EAEC } \\
(\mathbf{n}=37)\end{array}$} & & & & \\
\hline & $\mathbf{n}$ & $\%$ & $\mathbf{n}$ & $\%$ & $\mathbf{n}$ & $\%$ & & $\mathbf{n}$ & $\%$ & $\mathbf{n}$ & $\%$ & $\mathbf{n}$ & $\%$ & & \\
\hline aap & 163 & (87.6) & 191 & (75.2) & 354 & $(80.5)$ & 0.002 & 32 & (86.5) & 23 & $(62.2)$ & 55 & (74.3) & 0.03 & $n s$ \\
\hline irp2 & 155 & $(83.3)$ & 193 & (76.0) & 348 & $(79.1)$ & $n s$ & 18 & $(48.6)$ & 23 & $(62.2)$ & 41 & $(55.4)$ & $n s$ & 0.001 \\
\hline ast $A$ & 92 & $(49.5)$ & 104 & (40.9) & 196 & $(44.5)$ & $n s$ & 20 & $(54.1)$ & 11 & $(29.7)$ & 31 & (41.9) & $n s$ & $n s$ \\
\hline $\operatorname{aggA}$ & 38 & $(20.4)$ & 47 & (18.5) & 85 & (19.3) & $n s$ & 7 & (18.9) & 4 & (10.8) & 11 & (14.9) & $n s$ & $n s$ \\
\hline aafA & 40 & $(21.5)$ & 33 & (13.0) & 73 & (16.6) & 0.020 & 5 & (13.5) & 1 & (2.7) & 6 & (8.1) & $n s$ & 0.039 \\
\hline pet & 36 & (19.4) & 32 & (12.6) & 68 & (15.5) & $n s$ & 7 & (18.9) & 2 & $(5.4)$ & 9 & (12.2) & $n s$ & $n s$ \\
\hline pic & 109 & (58.6) & 132 & $(52.0)$ & 241 & $(54.8)$ & $n s$ & 22 & (59.5) & 20 & $(54.1)$ & 42 & $(56.8)$ & $n s$ & $n s$ \\
\hline
\end{tabular}


Table 5. Prevalence of AMR phenotypes of EAEC isolated from diarrheal and non-diarrheal cases among Bolivian children.

\begin{tabular}{|c|c|c|c|c|c|c|c|c|c|c|c|c|c|c|c|c|}
\hline \multirow{3}{*}{ Drug class } & \multirow{3}{*}{ Antibiotics } & \multicolumn{7}{|c|}{ Diarrheal isolates (D) } & \multicolumn{7}{|c|}{ Non-diarrheal isolates (ND) } & \multirow{3}{*}{$\begin{array}{c}P \text { - } \\
\text { value } \\
\text { (D vs. } \\
\text { ND) }\end{array}$} \\
\hline & & \multicolumn{2}{|c|}{$\begin{array}{c}\text { t-EAEC } \\
(172)\end{array}$} & \multicolumn{2}{|c|}{$\begin{array}{c}\text { a-EAEC } \\
(239)\end{array}$} & \multicolumn{2}{|c|}{$\begin{array}{c}\text { Total } \\
(n=411)\end{array}$} & \multirow{2}{*}{$\begin{array}{c}P \text { - } \\
\text { value } \\
\text { (D) }\end{array}$} & \multicolumn{2}{|c|}{ t-EAEC (30) } & \multicolumn{2}{|c|}{ a-EAEC (27) } & \multicolumn{2}{|c|}{ Total $(n=57)$} & \multirow{2}{*}{$\begin{array}{c}P \text { - } \\
\text { value } \\
\text { (ND) }\end{array}$} & \\
\hline & & $\mathbf{n}$ & $(\%)$ & $\mathbf{n}$ & $(\%)$ & $\mathbf{n}$ & $(\%)$ & & $\mathbf{n}$ & $(\%)$ & $\mathbf{n}$ & $(\%)$ & $\mathbf{n}$ & $(\%)$ & & \\
\hline \multirow[t]{2}{*}{ Penicillins } & $\mathbf{A M}$ & 158 & (91.9) & 226 & $(94.6)$ & 384 & $(93.4)$ & $n s$ & 28 & (93.3) & 21 & $(77.8)$ & 49 & $(86.0)$ & $n s$ & $n s$ \\
\hline & SAM & 88 & $(51.2)$ & 128 & $(53.6)$ & 216 & $(52.6)$ & $n s$ & 18 & $(60.0)$ & 13 & $(48.1)$ & 31 & $(54.4)$ & $n s$ & $n s$ \\
\hline \multirow[t]{2}{*}{ Cephalosporins } & FOX & 24 & $(14.0)$ & 20 & $(8.4)$ & 44 & $(10.7)$ & $n s$ & 6 & $(20.0)$ & 6 & $(22.2)$ & 12 & $(21.1)$ & $n s$ & 0.0468 \\
\hline & CTX & 12 & $(7.0)$ & 6 & $(2.5)$ & 18 & (4.4) & 0.0447 & 3 & $(10.0)$ & 4 & $(14.8)$ & 7 & (12.3) & $n s$ & 0.0023 \\
\hline Chloramphenicol & CLO & 38 & $(22.1)$ & 54 & $(22.6)$ & 92 & $(22.4)$ & $n s$ & 5 & (16.7) & 5 & $(18.5)$ & 10 & (17.5) & $n s$ & $n s$ \\
\hline \multirow[t]{2}{*}{ Fluoroquinolones } & CIP & 1 & $(0.6)$ & 4 & $(1.7)$ & 5 & $(1.2)$ & $n s$ & 2 & $(6.7)$ & 1 & $(3.7)$ & 3 & $(5.3)$ & $n s$ & $n s$ \\
\hline & NAL & 30 & (17.4) & 49 & $(20.5)$ & 79 & (19.2) & $n s$ & 9 & $(30.0)$ & 6 & $(22.2)$ & 15 & $(26.3)$ & $n s$ & $n s$ \\
\hline Tetracyclines & TE & 100 & $(58.1)$ & 115 & $(48.1)$ & 215 & $(52.3)$ & $n s$ & 19 & $(63.3)$ & 12 & (44.4) & 31 & $(54.4)$ & $n s$ & $n s$ \\
\hline \multirow[t]{2}{*}{ Sulphonamides } & STX & 117 & $(68.0)$ & 189 & (79.1) & 306 & $(74.5)$ & $n s$ & 21 & $(70.0)$ & 10 & (37.0) & 31 & $(54.4)$ & $n s$ & 0.0024 \\
\hline & MDR & 96 & $(55.8)$ & 153 & $(64.0)$ & 249 & $(60.6)$ & $n s$ & 19 & $(63.3)$ & 11 & $(40.7)$ & 30 & $(52.6)$ & $n s$ & $n s$ \\
\hline
\end{tabular}

AM, ampicillin; SAM, ampicillin-sulbactam; STX, sulfamethoxazole-trimethoprim; C, chloramphenicol;

FOX, cefoxitin; CIP, ciprofloxacin; NA, nalidixic acid; TE, tetracycline; CTX, cefotaxime.

MDR 
a)
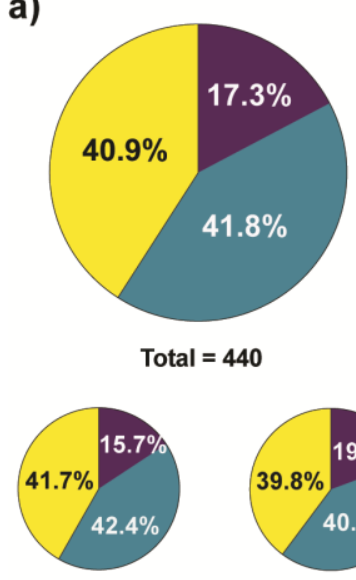

a-EAEC $=254$

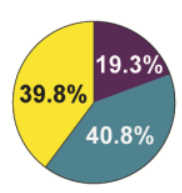

$\mathrm{tEAEC}=186$ b)

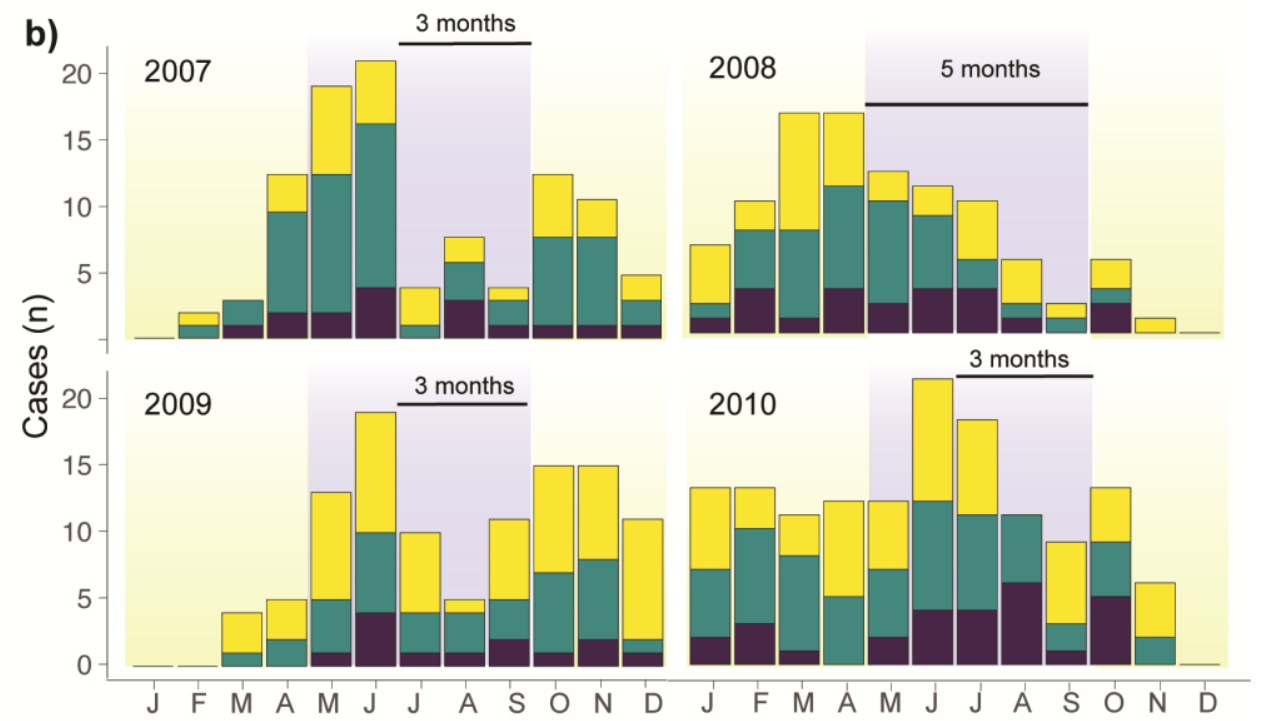

c)

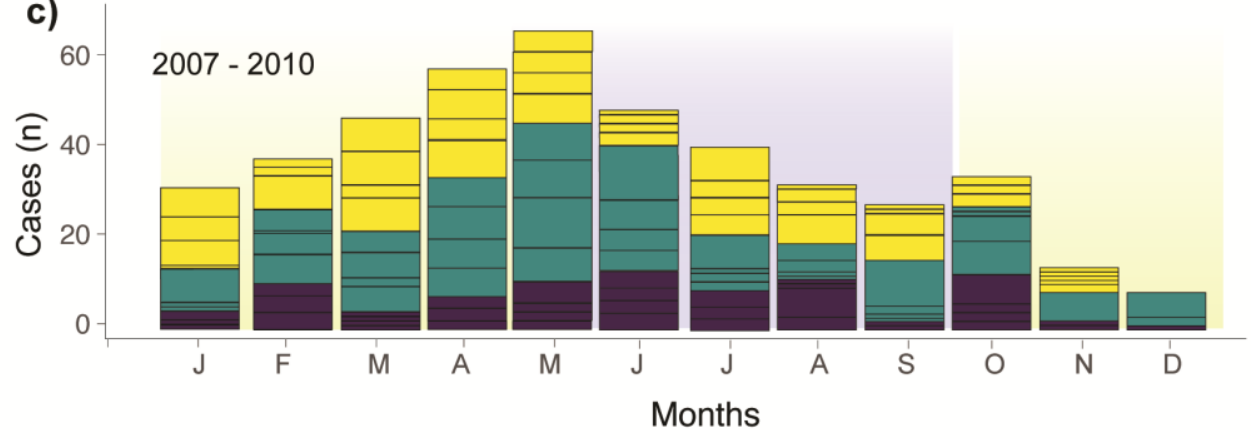

Figure 1. Age-wise and seasonal distribution of EAEC isolated from the stool samples of Bolivian children with acute diarrhea. a) Age group stratification of EAEC isolated from diarrheal and nondiarrheal cases. b) Seasonal distribution of age groups of EAEC isolates from diarrheal cases broken down per year or (c) accumulated. 


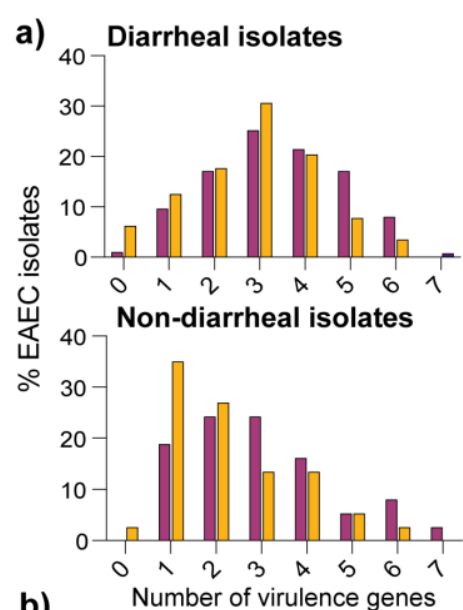

c)
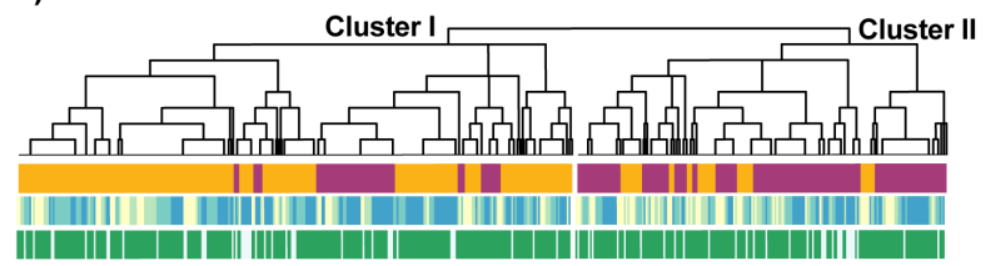

b)
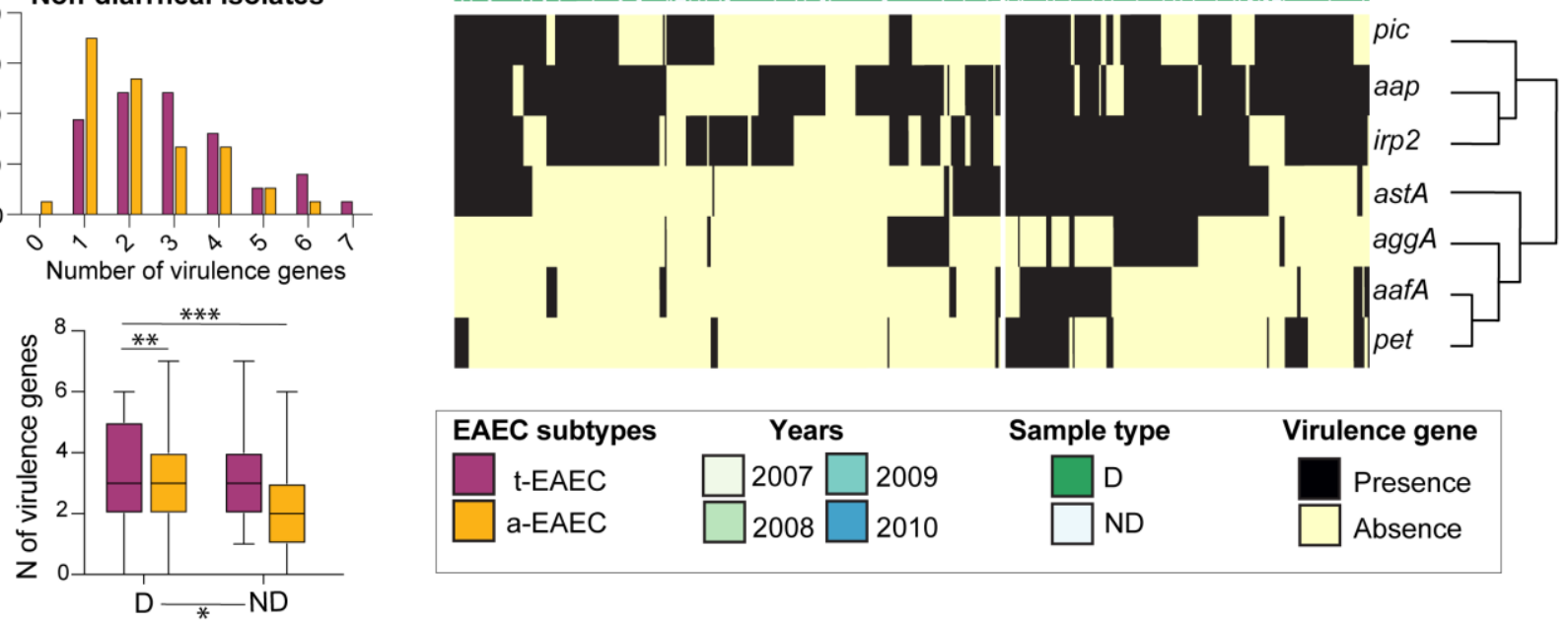

Figure 2. Characterization of virulence genes of EAEC isolates. a) The number of virulence genes found in diarrheal and non-diarrheal EAEC isolates. (b) Comparison of the average of virulence genes per isolate between groups (c) Heatmap and hierarchal clustering of virulence gene presence and absence across EAEC isolates. Genes were clustered by similarity using Pearson coefficients. 
a)Diarrheal isolates (D) b)
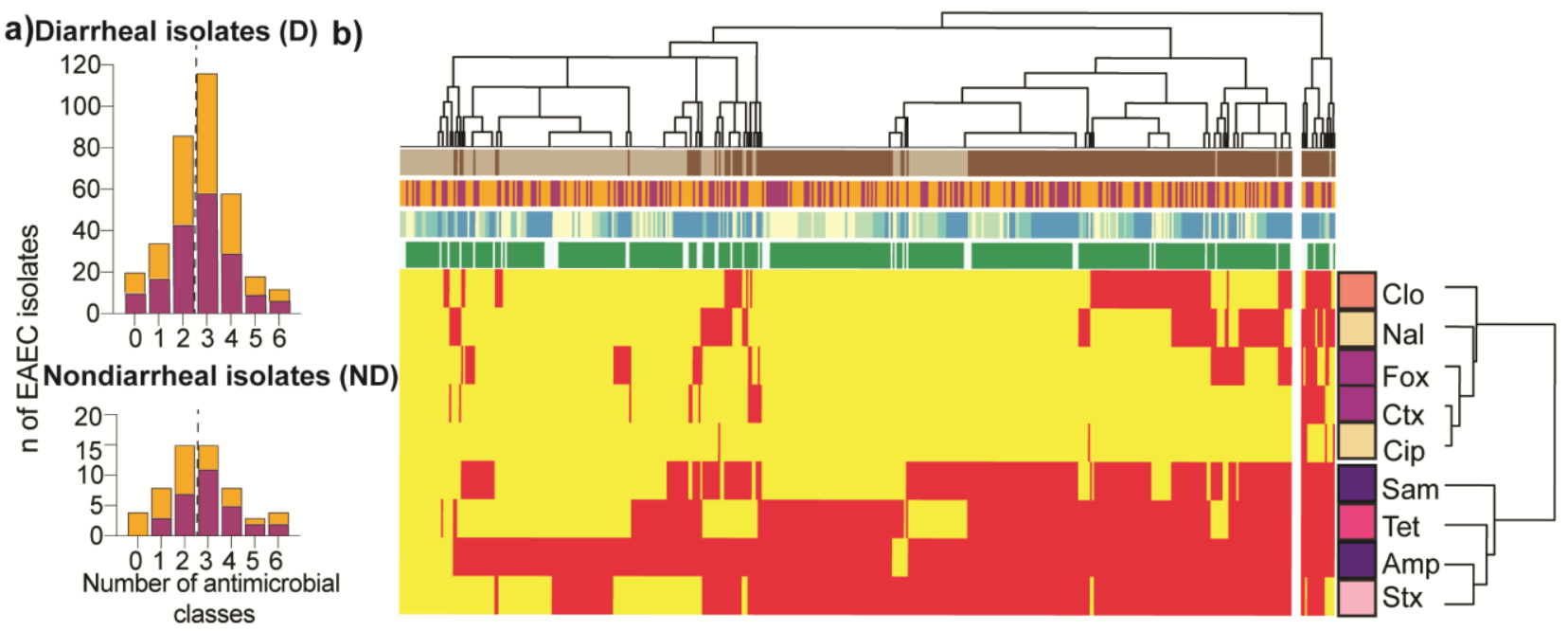

\begin{tabular}{|c|c|c|c|c|c|c|c|}
\hline EAEC subtypes & Yea & & Sample type & AMR & MDR patter & \multicolumn{2}{|c|}{ Antimicrobial classes } \\
\hline t-EAEC & 2007 & 2009 & D & \multirow{3}{*}{$\begin{array}{l}\text { Resistant } \\
\text { Sensitive }\end{array}$} & \multirow{3}{*}{$\begin{array}{l}\text { MDR } \\
\text { non-MDR }\end{array}$} & \multirow{3}{*}{$\begin{array}{l}\text { Penicillins } \\
\text { Cephalosporins } \\
\text { Tetracyclines }\end{array}$} & Chloramphenicols \\
\hline a-EAEC & 2008 & 2010 & ND & & & & Fluoroquinolones \\
\hline & & & & & & & Sulphonamides \\
\hline
\end{tabular}

Figure 3. Prevalence of AMR phenotypes from t-EAEC and a-EAEC isolated from diarrheal and non-diarrheal cases. a) Histograms illustrating the number of drug classes to which t-EAEC and aEAEC isolates were phenotypically resistant. b) the percentage of AMR phenotypes stratified by year.

$\mathrm{D}=$ diarrheal; $\mathrm{ND}=$ non-diarrheal 


\section{References:}

1. Global, regional, and national age-sex specific all-cause and cause-specific mortality for 240 causes of death, 1990-2013: a systematic analysis for the Global Burden of Disease Study 2013. Lancet. 2015;385(9963):117-71.

2. Okeke IN, Nataro JP. Enteroaggregative Escherichia coli. The Lancet Infectious Diseases. 2001;1(5):304-13.

3. Steiner TS, Lima AAM, Nataro JP, Guerrant RL. Enteroaggregative Escherichia coli Produce Intestinal Inflammation and Growth Impairment and Cause Interleukin-8 Release from Intestinal Epithelial Cells. The Journal of Infectious Diseases. 1998;177(1):88-96.

4. Lima AAM, Moore SR, Barboza MS, Jr, Soares AM, Schleupner MA, Newman RD, et al. Persistent Diarrhea Signals a Critical Period of Increased Diarrhea Burdens and Nutritional Shortfalls: A Prospective Cohort Study among Children in Northeastern Brazil. The Journal of Infectious Diseases. 2000;181(5):1643-51.

5. Moyo SJ, Maselle SY, Matee MI, Langeland N, Mylvaganam H. Identification of diarrheagenic Escherichia coli isolated from infants and children in Dar es Salaam, Tanzania. BMC Infect Dis. 2007;7:92-.

6. Sarantuya J, Nishi J, Wakimoto N, Erdene S, Nataro JP, Sheikh J, et al. Typical enteroaggregative Escherichia coli is the most prevalent pathotype among E. coli strains causing diarrhea in Mongolian children. J Clin Microbiol. 2004;42(1):133-9.

7. Gonzales L, Joffre E, Rivera R, Sjöling Å, Svennerholm A-M, Iñiguez V. Prevalence, seasonality, and severity of disease caused by pathogenic Escherichia coli in children with diarrhoea in Bolivia. J Med Microbiol. 2013;62(Pt 11):1697-706.

8. Croxen MA, Brett Finlay B. Molecular mechanisms of Escherichia coli pathogenicity. Nature Reviews Microbiology. 2010;8(1):26-38.

9. Rogawski ET, Guerrant RL, Havt A, Lima IFN, Medeiros PHQS, Seidman JC, et al. Epidemiology of enteroaggregative Escherichia coli infections and associated outcomes in the MALED birth cohort. PLOS Neglected Tropical Diseases. 2017;11(7):e0005798.

10. Hebbelstrup Jensen B, Olsen KEP, Struve C, Krogfelt KA, Petersen AM. Epidemiology and Clinical Manifestations of Enteroaggregative Escherichia coli. Clinical Microbiology Reviews. 2014;27(3):614-30.

11. Nataro JP, Kaper JB. Diarrheagenic Escherichia coli. Clinical Microbiology Reviews. 1998;11(1):142-201.

12. Ikumapayi UN, Boisen N, Hossain MJ, Betts M, Lamin M, Saha D, et al. Identification of Subsets of Enteroaggregative Escherichia coli Associated with Diarrheal Disease among Under 5 Years of Age Children from Rural Gambia. Am J Trop Med Hyg. 2017;97(4):997-1004.

13. Petro CD, Duncan JK, Seldina YI, Allué-Guardia A, Eppinger M, Riddle MS, et al. Genetic and Virulence Profiles of Enteroaggregative Escherichia coli (EAEC) Isolated From Deployed Military Personnel (DMP) With Travelers' Diarrhea. Frontiers in Cellular and Infection Microbiology. 2020;10. 
14. Pablo, Herbert. Enteroaggregative Escherichia coli (EAEC): A Cause of Acute and Persistent Diarrhea of Worldwide Importance. 2010;202(4):503-5.

15. Piva IC, Pereira AL, Ferraz LR, Silva RSN, Vieira AC, Blanco JE, et al. Virulence markers of enteroaggregative Escherichia coli isolated from children and adults with diarrhea in Brasília, Brazil. J Clin Microbiol. 2003;41(5):1827-32.

16. Hebbelstrup Jensen B, Poulsen A, Hebbelstrup Rye Rasmussen S, Struve C, Engberg JH, FriisMøller A, et al. Genetic Virulence Profile of Enteroaggregative Escherichia coli Strains Isolated from Danish Children with Either Acute or Persistent Diarrhea. Frontiers in Cellular and Infection Microbiology. 2017;7(230).

17. Dudley EG, Thomson NR, Parkhill J, Morin NP, Nataro JP. Proteomic and microarray characterization of the AggR regulon identifies a pheU pathogenicity island in enteroaggregative Escherichia coli. Molecular Microbiology. 2006;61(5):1267-82.

18. Lima IFN, Boisen N, Silva JDQ, Havt A, De Carvalho EB, Soares AM, et al. Prevalence of enteroaggregative Escherichia coli and its virulence-related genes in a case-control study among children from north-eastern Brazil. 2013;62(Pt_5):683-93.

19. Boisen N, Scheutz F, Rasko DA, Redman JC, Persson S, Simon J, et al. Genomic characterization of enteroaggregative Escherichia coli from children in Mali. $J$ Infect Dis. 2012;205(3):431-44.

20. Mandomando I, Vubil D, Boisen N, Quintó L, Ruiz J, Sigaúque B, et al. Escherichia coli ST131 clones harbouring AggR and AAF/V fimbriae causing bacteremia in Mozambican children: Emergence of new variant of fimH27 subclone. PLOS Neglected Tropical Diseases. 2020;14(5):e0008274.

21. Boisen N, Struve C, Scheutz F, Krogfelt KA, Nataro JP. New adhesin of enteroaggregative Escherichia coli related to the Afa/Dr/AAF family. Infect Immun. 2008;76(7):3281-92.

22. Czeczulin JR, Balepur S, Hicks S, Phillips A, Hall R, Kothary MH, et al. Aggregative adherence fimbria II, a second fimbrial antigen mediating aggregative adherence in enteroaggregative Escherichia coli. Infect Immun. 1997;65(10):4135-45.

23. Bernier C, Gounon P, Le Bouguénec C. Identification of an Aggregative Adhesion Fimbria (AAF) Type III-Encoding Operon in Enteroaggregative <em>Escherichia coli</em> as a Sensitive Probe for Detecting the AAF-Encoding Operon Family. Infection and Immunity. 2002;70(8):4302-11.

24. Morin N, Santiago AE, Ernst RK, Guillot SJ, Nataro JP. Characterization of the AggR regulon in enteroaggregative Escherichia coli. Infect Immun. 2013;81(1):122-32.

25. Sheikh J, Czeczulin JR, Harrington S, Hicks S, Henderson IR, Le Bouguénec C, et al. A novel dispersin protein in enteroaggregative Escherichia coli. J Clin Invest. 2002;110(9):1329-37.

26. Nishi J, Sheikh J, Mizuguchi K, Luisi B, Burland V, Boutin A, et al. The Export of Coat Protein from Enteroaggregative Escherichia coli by a Specific ATP-binding Cassette Transporter System. 2003;278(46):45680-9.

27. Savarino SJ, McVeigh A, Watson J, Cravioto A, Molina J, Echeverria P, et al. Enteroaggregative Escherichia coli Heat-Stable Enterotoxin Is Not Restricted to Enteroaggregative E. coli. 1996;173(4):1019-22.

28. Navarro-García F, Eslava C, Villaseca JM, López-Revilla R, Czeczulin JR, Srinivas S, et al. In Vitro Effects of a High-Molecular-Weight Heat-Labile Enterotoxin from Enteroaggregative $<$ em>Escherichia coli</em>. Infection and Immunity. 1998;66(7):3149-54. 
29. Henderson IR, Czeczulin J, Eslava C, Noriega F, Nataro JP. Characterization of pic, a secreted protease of Shigella flexneri and enteroaggregative Escherichia coli. Infect Immun. 1999;67(11):558796.

30. Schubert S, Rakin A, Karch H, Carniel E, Heesemann J. Prevalence of the "high-pathogenicity island" of Yersinia species among Escherichia coli strains that are pathogenic to humans. Infection and immunity. 1998;66(2):480-5.

31. Boisen N, Østerlund MT, Joensen KG, Santiago AE, Mandomando I, Cravioto A, et al. Redefining enteroaggregative Escherichia coli (EAEC): Genomic characterization of epidemiological EAEC strains. PLoS Negl Trop Dis. 2020;14(9):e0008613.

32. Estrada-Garcia T, Perez-Martinez I, Bernal-Reynaga R, Zaidi MB. Enteroaggregative : A Pathogen Bridging the North and South. Curr Trop Med Rep. 2014;1(2):88-96.

33. Munos MK, Fischer Walker CL, Black RE. The effect of oral rehydration solution and recommended home fluids on diarrhoea mortality. International Journal of Epidemiology. 2010;39(suppl_1):i75-i87.

34. Efunshile AM, Ezeanosike O, Nwangwu CC, König B, Jokelainen P, Robertson LJ. Apparent overuse of antibiotics in the management of watery diarrhoea in children in Abakaliki, Nigeria. BMC Infect Dis. 2019;19(1):275.

35. Hatchette TF, Farina D. Infectious diarrhea: when to test and when to treat. Canadian Medical Association Journal. 2011;183(3):339-44.

36. Toner E, Adalja A, Gronvall GK, Cicero A, Inglesby TV. Antimicrobial Resistance Is a Global Health Emergency. Health Security. 2015;13(3):153-5.

37. Ayukekbong JA, Ntemgwa M, Atabe AN. The threat of antimicrobial resistance in developing countries: causes and control strategies. Antimicrob Resist Infect Control. 2017;6:47.

38. Nataro JP, Yikang D, Cookson S, Cravioto A, Savarino SJ, Guers LD, et al. Heterogeneity of Enteroaggregative Escherichia Coli Virulence Demonstrated. The Journal of Infectious Diseases. 1995; 171(2):465-8.

39. Magiorakos AP, Srinivasan A, Carey RB, Carmeli Y, Falagas ME, Giske CG, et al. Multidrugresistant, extensively drug-resistant and pandrug-resistant bacteria: an international expert proposal for interim standard definitions for acquired resistance. Clin Microbiol Infect. 2012;18(3):268-81.

40. Arias B I, Cáceres R O, Figueroa V M, Huguet T J, Camiña Q M. Escherichia coli enteroagregativa en niños con diarrea de un hospital de Lima. Revista Peruana de Medicina Experimental y Salud Publica. 2004;21:176-8.

41. Ochoa TJ, Ruiz J, Molina M, Del Valle LJ, Vargas M, Gil AI, et al. High frequency of antimicrobial drug resistance of diarrheagenic Escherichia coli in infants in Peru. Am J Trop Med Hyg. 2009;81(2):296-301.

42. Torres AG. Pathogenic Escherichia Coli in Latin America: Bentham Science Publishers; 2010 2010. 264 p.

43. Lima AAM, Medeiros PHQS, Havt A. Enteroaggregative Escherichia coli subclinical and clinical infections. Curr Opin Infect Dis. 2018;31(5):433-9.

44. Torres AG. Escherichia coli in the Americas: Springer; 2016 2016/10/14. 384 p. 
45. Tokuda K, Nishi J, Imuta N, Fujiyama R, Kamenosono A, Manago K, et al. Characterization of typical and atypical enteroaggregative escherichia coli in Kagoshima, Japan: biofilm formation and acid resistance. Microbiol Immunol. 2010;54(6):320-9.

46. Okhuysen PC, Dupont HL. Enteroaggregative Escherichia coli (EAEC): a cause of acute and persistent diarrhea of worldwide importance. J Infect Dis. 2010;202(4):503-5.

47. Harrington SM, Dudley EG, Nataro JP. Pathogenesis of enteroaggregative Escherichia coli infection. FEMS Microbiol Lett. 2006;254(1):12-8.

48. Taborda RLM, Silva LAd, Orlandi PP, Batista FS, Rodrigues RS, Matos NB. CHARACTERIZATION OF ENTEROAGGREGATIVE ESCHERICHIA COLI AMONG DIARRHEAL CHILDRENIN WESTERN BRAZILIAN AMAZON. Arq Gastroenterol. 2018;55(4):390-6.

49. Jenkins C, Chart H, Willshaw GA, Cheasty T, Tompkins DS. Association of putative pathogenicity genes with adherence characteristics and fimbrial genotypes in typical enteroaggregative Escherichia coli from patients with and without diarrhoea in the United Kingdom. Eur J Clin Microbiol Infect Dis. 2007;26(12):901-6.

50. Regua-Mangia AH, Gomes TAT, Vieira MAM, Irino K, Teixeira LM. Molecular typing and virulence of enteroaggregative Escherichia coli strains isolated from children with and without diarrhoea in Rio de Janeiro city, Brazil. Journal of Medical Microbiology. 2009;58(4):414-22.

51. Grassly NC, Fraser C. Seasonal infectious disease epidemiology. Proceedings of the Royal Society B: Biological Sciences. 2006;273(1600):2541-50.

52. Chao DL, Roose A, Roh M, Kotloff KL, Proctor JL. The seasonality of diarrheal pathogens: A retrospective study of seven sites over three years. PLoS Negl Trop Dis. 2019;13(8):e0007211.

53. Claudia Canedo-Rosso Cintia BURB. Precipitation variability and its relation to climate anomalies in the Bolivian Altiplano. Int J Climatol. 2018;39(4):2096-107.

54. Jiang Z-D, Greenberg D, Nataro JP, Steffen R, DuPont HL. Rate of Occurrence and Pathogenic Effect of Enteroaggregative <em>Escherichia coli</em> Virulence Factors in International Travelers. Journal of Clinical Microbiology. 2002;40(11):4185-90.

55. Cennimo D, Abbas A, Huang DB, Chiang T. The prevalence and virulence characteristics of enteroaggregative Escherichia coli at an urgent-care clinic in the USA: a case-control study. Journal of Medical Microbiology. 2009;58(4):403-7.

56. Bafandeh S, Haghi F, Zeighami H. Prevalence and virulence characteristics of enteroaggregative Escherichia coli in a case-control study among patients from Iran. Journal of Medical Microbiology. 2015;64(5):519-24.

57. Huang DB, Mohamed JA, Nataro JP, DuPont HL, Jiang Z-D, Okhuysen PC. Virulence characteristics and the molecular epidemiology of enteroaggregative Escherichia coli isolates from travellers to developing countries. Journal of Medical Microbiology. 2007;56(10):1386-92.

58. Nüesch-Inderbinen MT, Hofer E, Hächler H, Beutin L, Stephan R. Characteristics of enteroaggregative Escherichia coli isolated from healthy carriers and from patients with diarrhoea. Journal of Medical Microbiology. 2013;62(12):1828-34.

59. Boll EJ, McCormick BA. A new understanding of enteroaggregative Escherichia coli as an inflammatory pathogen. Cell Adh Migr. 2012;6(5):413-8. 
60. Roche JK, Cabel A, Sevilleja J, Nataro J, Guerrant RL. Enteroaggregative Escherichia coli (EAEC) impairs growth while malnutrition worsens EAEC infection: a novel murine model of the infection malnutrition cycle. J Infect Dis. 2010;202(4):506-14.

61. Miranda M, Bento A, Aguilar AM. Malnutrition in all its forms and socioeconomic status in Bolivia. Public Health Nutr. 2020:1-8.

62. Elias WP, Uber AP, Tomita SK, Trabulsi LR, Gomes TAT. Combinations of putative virulence markers in typical and variant enteroaggregative Escherichia coli strains from children with and without diarrhoea. Epidemiology and Infection. 2002;129(1):49-55.

63. Czeczulin JR, Whittam TS, Henderson IR, Navarro-Garcia F, Nataro JP. Phylogenetic analysis of enteroaggregative and diffusely adherent Escherichia coli. Infect Immun. 1999;67(6):2692-9.

64. Villaseca JM, Hernández U, Sainz-Espuñes TR, Rosario C, Eslava C. Enteroaggregative Escherichia coli an emergent pathogen with different virulence properties. Rev Latinoam Microbiol. 2005;47(3-4):140-59.

65. Okeke IN, Lamikanra A, Czeczulin J, Dubovsky F, Kaper JB, Nataro JP. Heterogeneous Virulence of Enteroaggregative Escherichia coli Strains Isolated from Children in Southwest Nigeria. The Journal of Infectious Diseases. 2000;181(1):252-60.

66. Bouzari S, Jafari A, Azizi A, Oloomi M, Nataro JP. Short report: characterization of enteroaggregative Escherichia coli isolates from Iranian children. Am J Trop Med Hyg. 2001;65(1):134.

67. Kahali S, Sarkar B, Rajendran K, Khanam J, Yamasaki S, Nandy RK, et al. Virulence characteristics and molecular epidemiology of enteroaggregative Escherichia coli isolates from hospitalized diarrheal patients in Kolkata, India. J Clin Microbiol. 2004;42(9):4111-20.

68. Monteiro BT, Campos LC, Sircili MP, Franzolin MR, Bevilacqua LF, Nataro JP, et al. The dispersin-encoding gene (aap) is not restricted to enteroaggregative Escherichia coli. Diagn Microbiol Infect Dis. 2009;65(1):81-4.

69. Petro CD, Duncan JK, Seldina YI, Allué-Guardia A, Eppinger M, Riddle MS, et al. Genetic and Virulence Profiles of Enteroaggregative Escherichia coli (EAEC) Isolated From Deployed Military Personnel (DMP) With Travelers' Diarrhea. Frontiers in Cellular and Infection Microbiology. 2020;10(200).

70. Sheikh J, Czeczulin JR, Harrington S, Hicks S, Henderson IR, Le Bouguénec C, et al. A novel dispersin protein in enteroaggregative Escherichia coli. The Journal of Clinical Investigation. 2002;110(9):1329-37.

71. Nishi J, Sheikh J, Mizuguchi K, Luisi B, Burland V, Boutin A, et al. The export of coat protein from enteroaggregative Escherichia coli by a specific ATP-binding cassette transporter system. J Biol Chem. 2003;278(46):45680-9.

72. Boisen N, Struve C, Scheutz F, Krogfelt KA, Nataro JP. New adhesin of enteroaggregative Escherichia coli related to the Afa/Dr/AAF family. Infect Immun. 2008;76(7):3281-92.

73. Guerrieri CG, Pereira MF, Galdino ACM, Dos Santos ALS, Elias WP, Schuenck RP, et al. Typical and Atypical Enteroaggregative Are Both Virulent in the Model. Front Microbiol. 2019;10:1791.

74. Savarino SJ, Fasano A, Robertson DC, Levine MM. Enteroaggregative Escherichia coli elaborate a heat-stable enterotoxin demonstrable in an in vitro rabbit intestinal model. J Clin Invest. 1991;87(4):1450-5. 
75. Ménard L-P, Lussier JG, Lépine F, Paiva de Sousa C, Dubreuil JD. Expression, purification, and biochemical characterization of enteroaggregative Escherichia coli heat-stable enterotoxin 1. Protein Expr Purif. 2004;33(2):223-31.

76. Belkaid Y, Hand TW. Role of the Microbiota in Immunity and Inflammation. Cell. 2014;157(1):121-41.

77. Bruzzese E, Giannattasio A, Guarino A. Antibiotic treatment of acute gastroenteritis in children. F1000Research. 2018;7:193.

78. Guzman-Otazo J, Gonzales-Siles L, Poma V, Bengtsson-Palme J, Thorell K, Flach C-F, et al. Diarrheal bacterial pathogens and multi-resistant enterobacteria in the Choqueyapu River in La Paz, Bolivia. PLOS ONE. 2019;14(1):e0210735.

79. Rodas C, Mamani R, Blanco J, Blanco JE, Wiklund G, Svennerholm A-M, et al. Enterotoxins, colonization factors, serotypes and antimicrobial resistance of enterotoxigenic Escherichia coli (ETEC) strains isolated from hospitalized children with diarrhea in Bolivia. Braz J Infect Dis. 2011;15(2):1327.

80. Bartoloni A, Pallecchi L, Benedetti M, Fernandez C, Vallejos Y, Guzman E, et al. Multidrugresistant commensal Escherichia coli in children, Peru and Bolivia. Emerg Infect Dis. 2006;12(6):90713.

81. Sang WK, Oundo JO, Mwituria JK, Waiyaki PG, Yoh M, Iida T, et al. Multidrug-resistant enteroaggregative Escherichia coli associated with persistent diarrhea in Kenyan children. Emerg Infect Dis. 1997;3(3):373-4.

82. Ingle DJ, Levine MM, Kotloff KL, Holt KE, Robins-Browne RM. Dynamics of antimicrobial resistance in intestinal Escherichia coli from children in community settings in South Asia and subSaharan Africa. Nat Microbiol. 2018;3(9):1063-73.

83. Opintan JA, Bishar RA, Newman MJ, Okeke IN. Carriage of diarrhoeagenic Escherichia coli by older children and adults in Accra, Ghana. Trans R Soc Trop Med Hyg. 2010;104(7):504-6.

84. Nataro JP, Yikang D, Yingkang D, Walker K. AggR, a transcriptional activator of aggregative adherence fimbria I expression in enteroaggregative Escherichia coli. J Bacteriol. 1994;176(15):46919.

85. Yatsuyanagi J, Saito S, Sato H, Miyajima Y, Amano K, Enomoto K. Characterization of enteropathogenic and enteroaggregative Escherichia coli isolated from diarrheal outbreaks. J Clin Microbiol. 2002;40(1):294-7. 